\title{
Contact Potential that Recognizes the Correct Folding of Globular Proteins
}

\author{
Vladimir N. Maiorov and Gordon M. Crippen \\ College of Pharmacy, University of Michigan \\ Ann Arbor, MI 48109, U.S.A.
}

(Received 3 March 1992; accepted 26 May 1992)

\begin{abstract}
We have devised a continuous function of interresidue contacts in globular proteins such that the X-ray crystal structure has a lower function value than that of thousands of protein-like alternative conformations. Although we fit the adjustable parameters of the potential using only 10,000 alternative structures for a selected training set of 37 proteins, a grand total of 530,000 constraints was satisfied, derived from 73 proteins and their numerous alternative conformations. In every case where the native conformation is adequately globular and compact, according to objective criteria we have developed, the potential function always favors the native over all alternatives by a substantial margin. This is true even for an additional three proteins never used in any way in the fitting procedure. Conformations differing only slightly from the native, such as those coming from crystal structures of the same protein complexed with different ligands or from crystal structures of point mutants, have function values very similar to the native's and always less than those of alternatives derived from substantially different crystal structures. This holds for all 95 structures that are homologous to one or another of various proteins we used. Realizing that this potential should be useful for modeling the conformation of new protein sequences from the body of protein crystal structures, we suggest a test for deciding whether a nearly correct approximation to the native conformation has been found.
\end{abstract}

$\bar{K}$ eywords: protein structure prediction; protein folding; amino acid residue contacts; conformational potential functions: globular proteins

\section{Introduction}

The classical protein folding problem is to predict the three-dimensional conformation of a protein given only its amino acid sequence. Here, we consider a restricted version that we might call the multiple choice "recognition problem": given the amino acid sequence of a protein and a large selection of globular conformations that includes the correct native fold, choose the one native conformation. Such a situation naturally arises in attempting to predict a protein's conformation by homology modeling, where there may be several different ways to arrange variable loops. Other applications are the assessment of alternative conformations of a protein derived from nuclear magnetic resonance (n.m.r. $\dagger$ ) experiments, or choosing between different chain tracings through the electron density in the early stages of determining a protein's X-ray crystal structure.

\footnotetext{
$\dagger$ Abbreviations used: n.m.r., nuclear magnetic resonance; PDB, Brookhaven Protein Data Bank; r.m.s.d., root-mean-square deviation; CTS, complete training set; RTS, reduced training set.
}

A number of different researchers have suggested various criteria for the recognition problem, such as the number of hydrophobic contacts (Bryant \& Amzel, 1987). Novotny and co-workers (Novotny et $a l ., 1984,1988$ ) analyzed the accessible surface area in terms of its polar/apolar ratio and the distribution of this ratio for different amino acid sidechains, as well as atomic packing and empirical energy and free energy functions, in order to differentiate between a few examples of correct versus intentionally misfolded structures. Chiche and coworkers related solvation free energy (Eisenberg \& McLachlan, 1986) to the correctness of a protein fold using the observed approximately linear dependence of the solvation energy on the protein chain length (Chiche et al., 1990). One of the latest and most successful examples of the three-dimensional profile approach (Lüthy et al., 1992) discriminated between the correct and an incorrect fold for seven different proteins, judging from their relative scores and from the general relation between the seores of correct crystal structures and their chain lengths. Moreover, they were able to detect an incorrectly folded segment in an otherwise correct structure.

In the approaches cited so far, the goal has been 
to recognize the correct fold as better in some sense than only one or two alternative folds. We believe it is much more difficult to favor the native fold over large numbers of alternatives. Sippl and co-workers (Sippl, 1990; Hendlich et al., 1990) constructed a potential of mean force for the interactions among $C^{\beta}$ atoms from a survey of protein crystal structures that tended to prefer the native conformation of several proteins over some thousands of alternatives, but not in all cases. In our initial look at the problem (Crippen, 1991), we concluded that a discrete function of interresidue contacts could be constructed for some simple model cases that preferred the native conformation over absolutely all possible alternatives. When it came to extending this to real protein conformations, we produced a discrete contact potential based on the native and alternative conformations of only eight proteins that correctly preferred the native over tens of thousands of alternative for another 37 proteins. However, the remaining 11 proteins in our study were incorrectly predicted. For this level of success, it was important to define a contact in the way reiterated below, and to use relatively few adjustable parameters. In agreement with Sippl, extremely small proteins or oligopeptides, such as avian pancreatic peptide, were consistently difficult to account for, but the remaining erroneous proteins could be treated by including them in the training sct, thereby producing a similar number of other proteins that would not fit.

In this study, we have increased the total set of protein crystal structures from 56 to 109 , thereby creating a much more difficult fitting problem because each protein is presented with many more alternatives to choose from. Nevertheless, we are able to account for all the proteins we examined by learning to identify the kinds of protein native conformations that can be treated this way and by correctly dealing with homologous proteins.

\section{Methods}

The approach is basically the same as before (Crippen, 1991). Given a protein crystal structure, we note which residues are in contact, according to a carefully chosen definition. The correct crystal structure of a protein is taken to be its native or reference conformation, and many alternative conformations are generated by taking the atomic co-ordinates of all possible contiguous segments of the correct length from all the larger proteins in the data set. In each of these alternatives, there are a different set of contacts, of course, but if the native sequence is imposed on each alternative, we seek some potential function of the contacts that has a lower value for the reference than for any alternative

\section{(a) Protein structure data}

The total set of protein crystal structures we considered were the 109 polypeptide chains in the 15 October 1990 release of the Brookhaven Protein Data Bank (PDB) (Abola et al., 1987) with co-ordinates of $N, C^{\alpha}, C^{\prime}, C^{\beta}$ and $O$ atoms, and no obvious chain breaks in the middle, as in our previous study (Crippen, 1991). Disordered or unre-
Table 1

List of the reference proteins used in this work, sorted by $P D B$ code

\begin{tabular}{|c|c|c|c|c|}
\hline $\begin{array}{l}\text { PDB } \\
\text { code }\end{array}$ & $\begin{array}{l}\text { Ressol. } \\
(\mathbb{A}) \dagger\end{array}$ & $\begin{array}{l}\text { No. } \\
\text { residues }\end{array}$ & $\begin{array}{l}\text { Chain } \\
\text { ID } \ddagger\end{array}$ & Title and source \\
\hline $155 \mathrm{c}$ & $2 \cdot 5$ & 121 & & $\begin{array}{l}\text { Gytochrome c550. } \\
\text { P. denitrificans }\end{array}$ \\
\hline labp & $2 \cdot 4$ & 306 & & $\begin{array}{l}\text { L-Arubinose-binding protein, } \\
\quad \text { E. coli }\end{array}$ \\
\hline $\operatorname{lacx}$ & 20 & 108 & & Actinoxanthin, A. globisporus \\
\hline Ibds & - & 43 & & $\begin{array}{l}\text { Sea anemone anti- } \\
\text { hypertensive anti-viral } \\
\text { protein }\end{array}$ \\
\hline $1 \mathrm{bp} 2$ & $1 \cdot 7$ & 123 & & $\begin{array}{l}\text { Bovine pancreatic } \\
\text { phospholipase A2 }\end{array}$ \\
\hline $1 \mathrm{ce} 5$ & $2 \cdot 5$ & 83 & & Cytochrome c5, Azotobacter \\
\hline lecr & 1.5 & 111 & & Cytochrome $c$, rice \\
\hline lcrn & 1.5 & 46 & & Crambin, Ahyssinian cabbage \\
\hline \multirow[t]{2}{*}{ lese } & $1 \cdot 2$ & 6.3 & $\mathrm{I}$ & $\begin{array}{l}\text { Eglin C (complexed with } \\
\text { subtilisin Carlsberg) }\end{array}$ \\
\hline & & 274 & $\mathrm{E}$ & $\begin{array}{l}\text { Subtilisin Carlsberg } \\
\text { (complexed with eglin C) }\end{array}$ \\
\hline letf & $1 \cdot 7$ & 68 & & $\begin{array}{l}\text { L7/ L12 } 50 \mathrm{~S} \text { ribosomal } \\
\text { protein (C-terminal } \\
\text { domain), } E \text {. coli }\end{array}$ \\
\hline lets & $2 \cdot 7$ & 437 & & Pig eitrate synthase \\
\hline ley3 & $2 \cdot 5$ & 118 & & $\begin{array}{l}\text { Cytochrome } 03 \\
\text { D. desulfuricans }\end{array}$ \\
\hline leod & $1 \cdot 4$ & 136 & & $\begin{array}{l}\text { Hemoylobin (eryuhrocruorin, } \\
\text { deoxy), C. thummi thummi }\end{array}$ \\
\hline lest & $2 \cdot 5$ & 240 & & Porcine tosyl-elastase \\
\hline Ifdx & $2 \cdot 0$ & 54 & & Ferredoxin, $P$. aerogenes \\
\hline $1 \mathrm{f} \times 1$ & $2 \cdot 0$ & 147 & & Flavodoxin, D. vulgaris \\
\hline $\lg e n$ & $3 \cdot 0$ & 29 & & Porcine glucagon \\
\hline $\operatorname{lgcr}$ & $1 \cdot 6$ & 174 & & Calf $\gamma$-II erystallin \\
\hline lhip & $2 \cdot 0$ & 85 & & $\begin{array}{l}\text { High potential iron protein } \\
\text { (oxidized), C. vinosum }\end{array}$ \\
\hline \multirow[t]{2}{*}{$\operatorname{lhmg}$} & $3 \cdot 0$ & 175 & B & $\begin{array}{l}\text { Haemagglutinin, influenza } \\
\text { virus }\end{array}$ \\
\hline & & 328 & A & \\
\hline lhmq & $2 \cdot 0$ & 113 & & $\begin{array}{l}\text { Hemerythrir (met), } \\
\text { sipunculid worm }\end{array}$ \\
\hline lhoe & $2 \cdot 0$ & 74 & & $\alpha$-Amylase inhibitor, S. tendae \\
\hline lhvp & - & 99 & & Retrovirus HIV-I protease \\
\hline llh4 & $2 \cdot 0$ & 153 & & $\begin{array}{l}\text { Leghemoglobin (deoxy) } \\
\text { yellow lupin }\end{array}$ \\
\hline $11 \mathrm{yz}$ & $2-0$ & 129 & & Hen egg-white lysozyme \\
\hline $11 \times 1$ & $1 \cdot 5$ & 130 & & Human lysozyme \\
\hline limba & $1 \cdot \theta$ & 146 & & Sea hare myoglobin \\
\hline $1 \mathrm{mbd}$ & $1 \cdot 4$ & 153 & & Sperm whale myoglobin \\
\hline lpaz & 1.55 & 120 & & $\begin{array}{l}\text { Pseudoazurin foxidized, } \mathrm{Cu}^{2+} \\
\text { A. faecalis) }\end{array}$ \\
\hline $1 \mathrm{pcy}$ & $1 \cdot 6$ & 99 & & Plastocyanin $\left(\mathrm{Cu}^{2+}\right)$, poplar \\
\hline lpfk & $2 \cdot 4$ & 320 & & Phosphofruetokinase, E. coli \\
\hline lphh & $2 \cdot 3$ & 394 & & $\begin{array}{l}p \text {-Hydroxybenzoate } \\
\text { hydroxylase, } P \text {. fluorescens }\end{array}$ \\
\hline $1 p p 2$ & $2 \cdot 5$ & 122 & & $\begin{array}{l}\text { Calcium-free phospholipase } \\
\text { A-2, rattlesnake }\end{array}$ \\
\hline lppt & $1 \cdot 37$ & 36 & & Avian pancreatic polypeptide \\
\hline lpyp & 30 & 280 & & Yeast pyrophosphatase \\
\hline lrei & $2 \cdot 0$ & 107 & & $\begin{array}{l}\text { Human Bence-Jones } \\
\text { immunoglobulin variable } \\
\text { portion }\end{array}$ \\
\hline lrhd & 25 & 293 & & Bovine rhodanese \\
\hline $\operatorname{lnn} 3$ & $1 \cdot 45$ & 124 & & Bovine ribonuclease $\mathrm{A}$ \\
\hline $\operatorname{lsn} 3$ & $1 \cdot 8$ & 65 & & $\begin{array}{l}\text { Scorpion neurotoxin, variant } \\
\quad 3\end{array}$ \\
\hline Itim & $2 \cdot 5$ & 247 & & $\begin{array}{l}\text { Chicken triose phosphate } \\
\text { isomerase }\end{array}$ \\
\hline lwrp & $2 \cdot 2$ & 102 & & Bacterial TRP repressor \\
\hline $2 a b x$ & $2 \cdot 5$ & 74 & & $\begin{array}{l}\alpha \text {-Bungarotoxin, braided krait } \\
\text { venom }\end{array}$ \\
\hline 2aet & $1 \cdot 7$ & 218 & & Actinidin, kiwi fruit \\
\hline
\end{tabular}


Table 1 (continued)

\begin{tabular}{|c|c|c|c|c|}
\hline $\begin{array}{l}\text { PDB } \\
\text { code }\end{array}$ & $\begin{array}{l}\text { Resol. } \\
(\AA) \dagger\end{array}$ & $\begin{array}{l}\text { No. } \\
\text { residues }\end{array}$ & $\begin{array}{l}\text { Chain } \\
\text { ID } \ddagger\end{array}$ & Title and source \\
\hline 2alp & $1 \cdot 7$ & 198 & & $\begin{array}{l}\alpha \text {-Lytic protease, } \\
\text { L. enzymogenes }\end{array}$ \\
\hline $2 \mathbf{a z a}$ & $1 \cdot 8$ & 129 & & $\begin{array}{l}\text { Azurin (oxidized) } \\
\text { A. denitrificans }\end{array}$ \\
\hline $2 \mathrm{~b} 5 \mathrm{e}$ & $2 \cdot 0$ & 85 & & Bovine cytochrome $b 5$ \\
\hline $2 \mathrm{c} 2 \mathrm{c}$ & $2 \cdot 0$ & 112 & & $\begin{array}{l}\text { Cytochrome c2 (oxidized), } \\
\quad \text { R. rubrum }\end{array}$ \\
\hline $2 \mathrm{cab}$ & $2 \cdot 0$ & 256 & & $\begin{array}{l}\text { Human carbonic anhydrase } \\
\quad \text { (form B) }\end{array}$ \\
\hline $2 c c y$ & $1 \cdot 67$ & 127 & & $\begin{array}{l}\text { Cytochrome } c^{\prime} \\
\quad \text { R. molischianum }\end{array}$ \\
\hline $2 e d v$ & $1 \cdot 8$ & 107 & & Cytochrome $c 3, D$. vulgaris \\
\hline 2cna & $2 \cdot 0$ & 237 & & Concanavalin $\mathrm{A}$, jack bean \\
\hline 2 cyp & $1 \cdot 7$ & 293 & & $\begin{array}{l}\text { Yeast cytochrome } c \\
\text { peroxidase }\end{array}$ \\
\hline $2 \mathrm{fb} 4$ & $1 \cdot 9$ & 216 & $\mathrm{~L}$ & $\begin{array}{l}\text { Human immunoglobulin light } \\
\text { chain }\end{array}$ \\
\hline $2 \operatorname{gn} 5$ & $2 \cdot 3$ & 87 & & $\begin{array}{l}\text { Bacteriophage gene } 5 \\
\text { DNA-binding protein }\end{array}$ \\
\hline $2 \mathrm{hhb}$ & $1 \cdot 74$ & $\begin{array}{l}141 \\
146\end{array}$ & $\begin{array}{l}\text { A } \\
\mathrm{B}\end{array}$ & Human hemoglobin (deoxy) \\
\hline $2 \mathrm{lhb}$ & $2 \cdot 0$ & 149 & & $\begin{array}{l}\text { Sea lamprey hemoglobin } \mathrm{V} \\
\text { (cyano, met) }\end{array}$ \\
\hline $2 \mathrm{lzm}$ & $1 \cdot 7$ & 164 & & T4 phage lysozyme \\
\hline $2 \mathrm{mlt}$ & $2 \cdot 0$ & 26 & & Bee melittin \\
\hline 2ovo & $1 \cdot 5$ & 56 & & $\begin{array}{l}\text { Ovomucoid (third domain), } \\
\text { pheasant }\end{array}$ \\
\hline $2 \mathrm{pab}$ & $1 \cdot 8$ & 114 & & Human prealbumin \\
\hline 2pka & $2 \cdot 05$ & $\begin{array}{r}80 \\
152\end{array}$ & $\begin{array}{l}\text { A } \\
\text { B }\end{array}$ & Porcine kallikrein A \\
\hline 2rhe & $1 \cdot 6$ & 114 & & $\begin{array}{l}\text { Human } \lambda \text { immunoglubulin } \\
\text { variable domain } \\
\text { (Bence-Jones) }\end{array}$ \\
\hline $2 s g a$ & $1 \cdot 5$ & 181 & & Proteinase A, S. griseus \\
\hline $2 \operatorname{sins}$ & $1 \cdot 5$ & 141 & & Staphylococcal nuclease \\
\hline 2sod & $2 \cdot 0$ & 151 & & $\begin{array}{l}\text { Bovine } \mathrm{Cu}, \mathrm{Zn} \text { superoxide } \\
\text { dismutase }\end{array}$ \\
\hline $2 \mathrm{ssi}$ & $2 \cdot 6$ & 107 & & $\begin{array}{l}\text { Streptomyces subtilisin } \\
\text { inhibitor }\end{array}$ \\
\hline $2 \mathrm{stv}$ & $2 \cdot 50$ & 184 & & $\begin{array}{l}\text { Tobacco necrosis virus coat } \\
\text { protein }\end{array}$ \\
\hline 2 taa & $3 \cdot 0$ & 478 & & Taka-amylase A, A. oryzae \\
\hline $351 \mathrm{c}$ & $1 \cdot 6$ & 82 & & $\begin{array}{l}\text { Cytochrome } e 551 \text { (oxidized) } \\
\text { P. aeruginosa }\end{array}$ \\
\hline 3adk & $2 \cdot 1$ & 194 & & Porcine adenylate kinase \\
\hline $3 e b x$ & $1 \cdot 4$ & 62 & & Sea snake erabutoxin B \\
\hline $3 \mathrm{fab}$ & $2 \cdot 0$ & 207 & $\mathbf{L}$ & $\begin{array}{l}\text { Human } \lambda \text { immunoglobulin } \\
\text { FAB }^{\prime}\end{array}$ \\
\hline & & 219 & H & \\
\hline $3 \mathrm{fxc}$ & $2 \cdot 5$ & 98 & & Ferredoxin, S. platensis \\
\hline $3 f \times n$ & 1.9 & 138 & & $\begin{array}{l}\text { Flavodoxin (oxidized), } \\
\text { Clostridium }\end{array}$ \\
\hline 3gap & $2 \cdot 5$ & 208 & & $\begin{array}{l}\text { Catabolite gene activator } \\
\text { protein, } E \text {. coli }\end{array}$ \\
\hline $3 g p d$ & $3 \cdot 5$ & 334 & & $\begin{array}{l}\text { Human D-glyceraldehyde- } \\
\text { 3-phosphate dehydrogenase }\end{array}$ \\
\hline 3grs & 1.54 & 461 & & Human glutathione reductase \\
\hline 3icb & $2 \cdot 3$ & 75 & & $\begin{array}{l}\text { Bovine calcium-binding } \\
\text { protein }\end{array}$ \\
\hline 3ins & 1.5 & $\begin{array}{l}21 \\
30\end{array}$ & $\begin{array}{l}\mathrm{A} \\
\mathrm{B}\end{array}$ & Pig insulin \\
\hline $3 p g k$ & $2 \cdot 5$ & 415 & & $\begin{array}{l}\text { Yeast phosphoglycerate } \\
\text { kinase }\end{array}$ \\
\hline $3 \mathrm{rp} 2$ & $1 \cdot 9$ & 224 & & Rat mast cell protease \\
\hline 4ape & $2 \cdot 1$ & 330 & & Endothiapepsin, fungal \\
\hline $4 \mathrm{dfr}$ & $1 \cdot 7$ & 159 & & $\begin{array}{l}\text { Dihydrofolate reductase, } \\
\text { E. coli }\end{array}$ \\
\hline 4fd1 & 1.9 & 106 & & Azotobacter ferrodoxin \\
\hline $4 \mathrm{mdh}$ & $2 \cdot 5$ & 333 & & $\begin{array}{l}\text { Porcine cytoplasmic malate } \\
\text { dehydrogenase }\end{array}$ \\
\hline
\end{tabular}

Table 1 (continued)

\begin{tabular}{|c|c|c|c|c|}
\hline $\begin{array}{l}\text { PDB } \\
\text { code }\end{array}$ & $\begin{array}{l}\text { Resol. } \\
(A) \dagger\end{array}$ & $\begin{array}{l}\text { No. } \\
\text { residues }\end{array}$ & $\begin{array}{l}\text { Chain } \\
\mathrm{ID}_{+}^{+}\end{array}$ & Title and source \\
\hline $4 \mathrm{pti}$ & 1.5 & 58 & & $\begin{array}{l}\text { Bovine pancreatic trypsin } \\
\text { inhibitor }\end{array}$ \\
\hline \multirow[t]{4}{*}{$4 \mathrm{rhv}$} & $3 \cdot 0$ & 40 & 4 & $\begin{array}{l}\text { Human rhinovirus } 14 \text { coat } \\
\text { protein }\end{array}$ \\
\hline & & 236 & 3 & \\
\hline & & 255 & 2 & \\
\hline & & 273 & 1 & \\
\hline 4 sbv & $2 \cdot 8$ & 199 & & $\begin{array}{l}\text { Southern bean mosaic virus } \\
\text { coat protein }\end{array}$ \\
\hline $4 \operatorname{tln}$ & $2 \cdot 3$ & 316 & & Bacterial thermolysin \\
\hline $5 \mathrm{cpa}$ & 1.54 & 307 & & Bovine carboxypeptidase $\mathrm{A} \alpha$ \\
\hline $5 \mathrm{cpv}$ & 16 & 108 & & $\begin{array}{l}\text { Carp calcium-binding } \\
\text { parvalbumin } B\end{array}$ \\
\hline $5 c y t$ & 1.5 & 103 & & Gytochrome $c$ (reduced), tuna \\
\hline $5 \mathrm{rxn}$ & $1 \cdot 20$ & 54 & & $\begin{array}{l}\text { Rubredoxin (oxidized, } \mathrm{Fe}^{3+} \text { ), } \\
\text { Clostridium }\end{array}$ \\
\hline 6ldh & $2 \cdot 0$ & 329 & & Dogfish lactate dehydrogenase \\
\hline \multirow[t]{2}{*}{ 7api } & $3 \cdot 0$ & 36 & B & $\begin{array}{l}\text { Human modified } \\
x \text {-1-antitrypsin }\end{array}$ \\
\hline & & 339 & A & \\
\hline $8 a d h$ & $2 \cdot 4$ & 374 & & $\begin{array}{l}\text { Horse apo-liver alcohol } \\
\text { dehydrogenase }\end{array}$ \\
\hline 8 cat & $2 \cdot 5$ & 498 & & Bovine catalase \\
\hline 9 pap & $1 \cdot 65$ & 212 & & $\begin{array}{l}\text { Papain (Cys25 oxidized), } \\
\text { Papaya }\end{array}$ \\
\hline $9 w g a$ & $1 \cdot 8$ & 170 & & Wheat-germ agglutinin \\
\hline
\end{tabular}

† A - sign denotes n.m.r. (lbds) and model (l bvp) protein structures for which the notion of the resolution is not applicable.

F In the case of more than 1 chain in a PDB file, the chain identifiers are given

solved residues at the $\mathrm{N}$ or $\mathrm{C}$ termini are not included in the polypeptide chains we consider here. For brevity, we will refer to those chains by their PDB code and the chain identifier in the PDB file (e.g. 3ins.A is the $A$ chain of insulin). The full name of each protein can be found in Table 1. Generally, we included only the aceurately deter mined ( $\leq 2.5 \AA$ nominal resolution: $1 \AA=0.1 \mathrm{~nm}$ ) structures, although some lower-resolution structures, having no interior chain breaks, were included in this study, sometimes to increase the number of alternative conformations we could generate, and sometimes to increase the number of short protein chains considered. We also included 2 other PDB entries that technically did not fulfil the $2.5 \AA$ resolution criterion: 1 bds is a structure determined by n.m.r. and distance geometry having unknown accuracy, and lhvp is a hypothetical conformation built by homology modeling. In the final analysis, these 2 caused no special problems. The 109 protein structures ranged from 21 residues for the shorter insulin chain 3ins.A to 498 residues for 8cat.A. However, we used only the smallest 86 chains as reference structures because these all had 255 or fewer residues. The limit of 255 is due to the database packing scheme we used, where each contact in each alternative encodes its sequence separation in one 8-bit byte. Even so, our total database of all contacts for all 691,165 alternatives of all the reference proteins required a few hundred negabyles of storage Thus, the 23 largest structures (2cab, 4rhv.l, lcse.E. lpyp, 1rhd, 2cyp, 1abp, 5cpa, 4tln, 1pfk.A, lhmg.A, 6ldh, 4ape, 4mdh.A, 4gpd.G, 7api.A, 8adh, 1phh, 3pgk, lets, 3grs, 2tta.A and 8cat.A) were used only for building alternative structures.

The 86 reference structures are those in Table 1 which have chain length less than 256 (also listed in Table 4 in 
Table 2

The 19 reference proteins used in the present work and their 95 homologues

\begin{tabular}{|c|c|c|c|}
\hline \multirow{2}{*}{$\begin{array}{l}\text { No. } \\
\text { residues }\end{array}$} & \multicolumn{2}{|c|}{ PDB codes and chain identifiers } & \multirow{2}{*}{$\begin{array}{l}\text { r.m.s.d } \\
\qquad(\AA) \|\end{array}$} \\
\hline & Reference ${ }^{\dagger}$ & Homologous $\ddagger$ & \\
\hline 58 & $4 p t i$ & $5 p t i$ & 0.59 \\
\hline 62 & $3 e b x$ & $5 \mathrm{ebx} \S$ & $0 \cdot 15$ \\
\hline 82 & $351 \mathrm{c}$ & $451 \mathrm{c}$ & $0 \cdot 03$ \\
\hline 99 & lpcy & $\begin{array}{l}2 \text { pcy 3pcy 4pcy 5pcy } \\
6 \text { pey }\end{array}$ & $0 \cdot 12$ \\
\hline 106 & $4 \mathrm{fdl}$ & $1 \mathrm{fd} 22 \mathrm{fd} 2$ & 0.20 \\
\hline 108 & $5 \mathrm{cpv}$ & $\operatorname{lodp} 4 m p v$ & $0 \cdot 27$ \\
\hline 112 & $2 \mathrm{c} 2 \mathrm{c}$ & $3 c 2 \mathrm{c}$ & 0.09 \\
\hline 124 & $\operatorname{lrn} 3$ & 5rsa 6rsa 7rsa & $0 \cdot 15$ \\
\hline 129 & $11 y z$ & $\begin{array}{r}\text { 1lzt } 2 \text { lym } 2 \text { lyz } 2 \text { lz2 } 2 \text { lzt } \\
\text { 3lym [3-8]lyz Ilym.A }\end{array}$ & $0 \cdot 35$ \\
\hline 136 & lecd & leca lecn leco & 0.06 \\
\hline 138 & $3 \mathrm{fxn}$ & $4 \mathrm{fxn}$ & $0 \cdot 21$ \\
\hline 146 & $\operatorname{lmba}$ & $2 \mathrm{mba} 3 \mathrm{mba} 4 \mathrm{mba}$ & $0 \cdot 21$ \\
\hline 153 & $\operatorname{llh} 4$ & $\operatorname{llh}[1-3] \operatorname{llh}[5-7] 2 \operatorname{lh}[1-7]$ & $0 \cdot 12$ \\
\hline 153 & linbu & $\begin{array}{l}5 m b n 1 m b 51 \mathrm{mbe} 1 \mathrm{mbi} \\
1 \mathrm{mbo} 4 \mathrm{mbn}\end{array}$ & $0 \cdot 41$ \\
\hline 159 & 4dfr.A & $7 \mathrm{dfr}$ & $0 \cdot 74$ \\
\hline 164 & $2 \mathrm{zm}$ & $\begin{array}{l}11[01-02] 11[04-10] \\
11[12-25] 11[27-35] \\
11 y d 3 \mathrm{zm}\end{array}$ & $0 \cdot 12$ \\
\hline 170 & 9 wga.A & 1wgc.A 2wgc.A 7wga.A & $0 \cdot 21$ \\
\hline 212 & 9 pap & 1 ppd & 0.18 \\
\hline 237 & $2 \mathrm{cna}$ & $3 \mathrm{cna}$ & 0.74 \\
\hline
\end{tabular}

$\uparrow$ The following reference proteins having homologies were excluded from the reduced training set: 1 pey, $4 \mathrm{fdl}$, 5epv, $3 \mathrm{fxn}$, $1 \mathrm{mba}$, Imbd, 4dfr.A, 2lzm, 9pap, 2ena (see Table 4).

\# Digits in square brackets mean the whole range of numbers, e.g. [3-8]lyz is 3lyz, 4lyz, ., 8lyz.

\& Even though neurotoxin $B, \ln x b$, is homologous to erabutoxins 3ebx and 5ebx, it nevertheless was excluded from this list because of noticeable shape distortion: $e_{\mathrm{g}}=1 \cdot 17$ and $e_{N}=1.54$

$\|$ This is the $\mathrm{C}^{\alpha}-\mathrm{C}^{\alpha}$ distance r.m.s.d. (eqn (9)), averaged over all the homologous structures.

order of chain length). In addition, 19 of these reference structures have one or more homologous structures, by which we denote other crystal structures of proteins having the same chain length and strong sequence identity or the same proteins in different crystal environments and/or complexed with different ligands. These were not used in any training set and served only to assess the quality and predictive power of the deduced contact potentials. In all, there are 95 homologous structures, as listed in Table 2 with their corresponding 19 reference structures. As in our previous work, we derived alterna tive conformations for each reference structure from all larger references and from the 23 very large structures. Consequently, the smallest references had more alternatives (16,521 for 3ins.A), but even the largest, $4 \mathrm{rhv} .2$, had 2127. The total number of alternatives for all reference proteins was 691,165 , an order of magnitude more than in our previous work.

\section{(b) Compactness}

As before, the goal is to construct a function of the interresidue contacts such that each reference structure has a lower function value than any of its alternatives, just as the native conformation of a real protein has a lower free energy than any kinetically accessible alternative conformation. Although we make no claim that the function we determine in this work resembles the real free energy, we will loosely refer to our function as the contact energy. Preliminary studies indicated that some proteins are particularly difficult to bring into agreement with our goal, perhaps because they are not adequately compact or globular, certainly necessary conditions for lattice models of proteins (Crippen, 1991). For example, if a polypeptide chain crystallizes as a dimer with many interchain contacts, it is unreasonable to use the co-ordinates of a monomer in isolation as a reference structure in developing our energy function, because the contacts that stabilize the conformation would not be included in our calculations.

In order to develop a quantitative criterion to decide the suitability of a structure for use as a reference, and generally in order to distinguish between compact and non-compact structures, we examined 2 functions of a conformer's radius of gyration, $r_{\mathrm{g}}$, and number of contacts, $N_{\mathrm{c}}:(1)$ the ratio $e_{\mathrm{g}}$ of the radius of gyration of the putative reference structure to the minimal radius of gyration $r_{\mathbf{g}}(\mathrm{min})$ over the set of all its alternatives:

$$
e_{\mathbf{g}}=r_{\mathbf{g}} / r_{\mathbf{g}}(\min )
$$

and (2) the ratio of the maximal number of contacts for all alternatives, $N_{c}(\max )$, to the number of contacts for the reference structure in question:

$$
e_{N}=N_{c}(\max ) / N_{\mathrm{c}} .
$$

Here, $N_{\mathrm{c}}$ corresponds to the discrete form of the contact function, as described below. The values of $r_{g}(\mathrm{~min})$ and $N_{c}(\max )$ were determined by examining all the alternatives corresponding to the given reference structure, all of which have the same number of residues, of course. We find by linear regression over all our reference structures that the minimal radius of gyration depends on the number of amino acid residues $N_{\text {res }}$ as follows:

$$
r_{\mathrm{g}}(\min )=-1 \cdot 26+2 \cdot 79\left(N_{\text {res }}\right)^{1 / 3}
$$

with correlation coefficient of 0.997 . Another way to estimate the minimal possible radius of gyration as a function of $N_{\text {res }}$ is to model a globular protein as an ellipsoid of rotation (Damaschun et al., 1969) with mean partial volume of $134 \AA^{3} /$ residue. Then the minimal radius of gyration is achieved at unit eccentricity, i.e. spherical shape, giving the same functional form as eqn (3), but changing the coefficients from -1.26 and 279 to 0 and $2 \cdot 46$, respectively. The $r_{g}(\mathrm{~min})$ values resulting from the 2 functions differ by less than $6 \%$ over the range of $N_{\text {res }}$ considered, but the ellipsoid model curve fits the data slightly worse. Consequently, we used the empirical eqn (3) as our estimated minimal radius of gyration. Similarly, we find that the maximal number of contacts fits the linear regression equation:

$$
N_{c}(\max )=-53 \cdot 17+4 \cdot 25 N_{\text {res }}
$$

with correlation coefficient 0.992 . Note that the slope value of 4.25 indirectly bears out the correctness of the cutoff distances described below for specifying contacts; we really have something like the first co-ordination sphere for each residue in a contact.

We find that the position of a given protein structure on the $e_{\mathrm{g}}$ versus $e_{N}$ diagram (Fig. 1) accurately reflects the degree and nature of its compactness. Most interesting here is the clear evidence for the existence of 2 types of non-compactness: one characterized by noticeably larger values of $r_{\mathrm{g}}$ compared with its minimal value, and the second type marked by a definitely smaller number of 


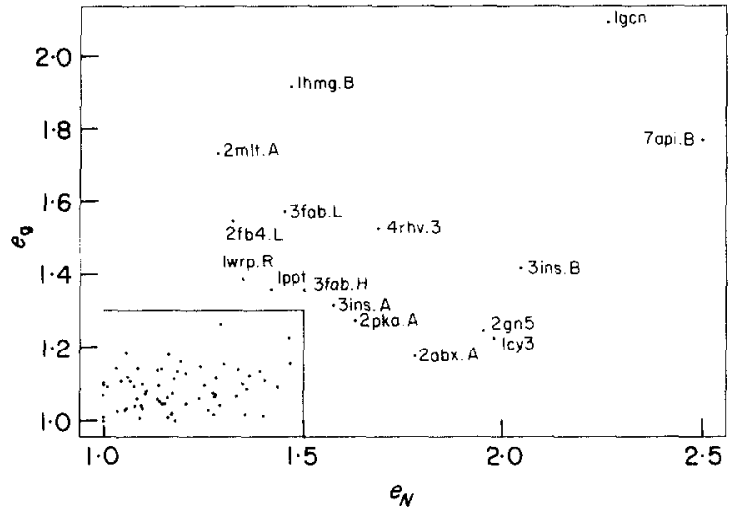

Figure 1. Diagram of $e_{\mathrm{g}}$ versus $e_{N}$ (see the text) to characterize the compactness of the 86 reference protein structures in terms of radius of gyration and number of contacts. The 16 non-compact structures exceeding the marked limits $e_{N}<1.50$ and $e_{\mathrm{g}}<1.30$ are indicated by their corresponding PDB codes and chain identifiers. One more extremely non-compact structure, $4 \mathrm{rhv} .4$, is off scale a.t $e_{N}=4.52$ and $e_{B}=2.54$

contacts $N_{\mathrm{c}}$ compared with the maximum possible for a polypeptide chain of the given length. These 2 types of non-compactness may both occur separately, e.g. high radius of gyration for 2mlt.A $\left(e_{N}=1.28, e_{\mathrm{g}}=1.73\right)$ and $1 \mathrm{hmg} . \mathrm{B}\left(e_{N}=1.47, e_{\mathrm{g}}=1.92\right)$; or low number of contacts for $2 \mathrm{gn} 5\left(e_{N}=1.95, \quad e_{\mathrm{g}}=1.25\right)$ and 1cy3 $\left(e_{N}=1.98\right.$, $\left.e_{\mathrm{g}}=1 \cdot 23\right)$; and simultaneously, e.g. for $\operatorname{lgen}\left(e_{N}=2 \cdot 26\right.$, $\left.e_{\mathrm{g}}=2.09\right)$ and 7 api.B $\left(e_{N}=2.50, e_{\mathrm{g}}=1 \cdot 77\right)$, as shown in Fig. 1. Clearly, most of the proteins are rather compact, being clustered in the lower left part of the diagram, while 17 proteins obviously have non-compact conformations. We chose:

$$
e_{N}<1.5 \text { and } e_{\mathrm{g}}<1.3
$$

as the requirements for compactness. We realize that the distribution in Fig. 1 is fairly continuous throughout the diagram, and therefore these limits are somewhat arbitrary. However, we employ them in this work because such a differentiation helps us determine the desired energy function, and it is also in good agreement with visual inspections of the protein folds. Note that while we require the reference structures to be compact according to this definition, the alternative conformations have no such constraint. In fact, 10 to $20 \%$ of the alternatives for each reference protein turn out to be compact.

In order to use eqn (5) for a particular protein structure having chain length $N_{\text {res }}$, one needs to know $r_{g}(\min )$ and $N_{\mathrm{c}}$ (max). The direct way is to generate the many thousands of alternative structures and calculate $r_{\mathrm{g}}$ and $N_{\mathrm{c}}$ for each. Not only is this tedious, but for large $N_{\text {res }}$, there are sometimes substantial deviations from the very regular trend shown for smaller proteins. The reason is that the number of alternatives decreases as the chain length increases, simply because we are dealing with a fixed number of proteins from which to generate alternatives. Consequently, now that we have established the accurate relations given in eqns (3) and (4), we use them in all subsequent calculations to quickly obtain $r_{g}(\min )$ and $N_{\mathrm{c}}(\max )$.

\section{(c) Calculations}

As in our previous study, we have evaluated conforma tions according to the interresidue contacts formed. The exact definition of a contact we continue to use (see Table 3 ) is designed to be applicable even if the sequence of a given conformation is changed. We consider only the backbone $\mathrm{N}, \mathrm{C}^{\prime}$ and $\mathrm{O}$ atoms plus the side-chain $\mathrm{C}^{\beta^{\prime}}$, even building in an artificial $C^{\beta}$ if the original residue is Gly Then a backbone-backbone contact is counted whenever $d(\mathrm{O}, \mathrm{N})<3 \cdot 2 \AA$ and $d(\mathrm{C}, \mathrm{N})>3.9 \AA ;$ a backbone-sidechain contact requires $d\left(\mathrm{~N}\right.$ or $\left.\mathrm{O}, \mathrm{C}^{\beta}\right)<5 \cdot 0 \AA$ and no other atom between the interacting pair closer than $1.4 \AA$ to the line segment joining them; and a side-chain-side-chain contact requires $d\left(\mathrm{C}^{\beta}, \mathrm{C}^{\beta}\right)<9 \cdot 0 \AA$ and similarly no interfering atom between them. Interactions must be between residues differing by at least 3 in sequence. Backbone atoms involved in contacts are ascribed to residue type Gly, but side-chain atoms correspond to their correct residue types.

Throughout this work we have assumed the contact potential function $E$ for a given protein conformation is a sum of the values $\varepsilon$ assigned to the individual contacts:

$$
E=\sum_{\substack{\text { contact residues } \\ i \text { and } j}} \varepsilon(\text { elass }(i), \text { class }(j),|i-j|),
$$

where the terms depend on the same very detailed standard classification according to sequence separation and residue type classes proposed earlier (Table 2 in Crippen (1991) and Table 5, here). This classification is a plausible one that groups together helix-formers versus helix breakers for short-range (i.e. sequence separation $\leq 4$ ) interactions, and hydrophobic versus hydrophilic residues for long-range interactions. We assume the importance of a contact does not depend on which residue is higher in sequence, so the interaction matrices in Table 5 are all symmetric, and there are a total of 84 parameters to adjust (4 separation ranges, each having 21 interaction parameters among 7 classes of amino acid).

In the preceding work (Crippen, 1991) we required only that

$$
E \text { (reference) } \leq E \text { (alternative) }
$$

for each reference and all alternatives of each reference. Now we demand that strict inequality hold by a margin $T_{k}$ for the $k$ th alternative given by:

$$
T_{k}=q D_{k} \text {. }
$$

Here, $q$ is an empirically adjusted coefficient (see below) and $D_{k}$ is the root-mean-square distance deviation (r.m.s.d.) between the reference and the $k$ th alternative structure:

$$
D=\left[\frac{\sum_{i<j}\left(d_{i j}-d_{i j}^{\prime}\right)^{2}}{N_{\mathrm{res}}\left(N_{\mathrm{res}}-1\right) / 2}\right]^{1 / 2},
$$

where $d_{i j}$ and $d_{i j}^{\prime}$ are the distances between the $i$ th and $j$ th $C^{\alpha}$ atoms in the reference and alternative structures. respectively. Of course, one may use the co-ordinatebased r.m.s.d. (McLachlan, 1979) instead of eqn (9), but because it makes no difference in this work, we chose the more easily calculated distance r.m.s.d. Thus, for a given reference structure and its $k$ th alternative, we require

$$
E(k \text { th alternative })-E(\text { reference }) \geq T_{k} \text {. }
$$

The underlying idea here is to make the energy of an alternative lie above that of the corresponding reference structure by at least some minimal margin that increases linearly with their conformational difference. Test computations showed that choosing a very small positive value for $q$ reduces eqn (10) to approximately eqn (7), makes the set of inequalities easier to solve, leads to very similar 
energies for the reference structure and some of its alter natives, and leaves no room on the energy scale between the reference structure and the lowest alternative for the homologous proteins, which are expected to scatter in this range. On the other hand, too large a $q$ caused a marked increase in the computer processor unit time required to find a solution for the set of inequalities. A reasonable compromise was $q=3$, the value used throughout this work. Although our potential function is required to have the free energy-like property of favoring the native conformation, eqn (10) has no relation to physical energy or temperature scales. Therefore the units for $E$ and $q$ are arbitrary. It turned out that the method used in our previous work to solve homogeneous sets of inequalities (Jurs, 1986), as in eqn (7), could be applied to sets of inhomogeneous inequalities, as in eqn (10), and was therefore used in all that follows.

Our procedure for determining the terms consists of the following 3 steps. (1) Simply directly solving the entire set of 690,000 linear inequalities of the form in eqn (10) is hopelessly slow. At the solution, only a relatively small number of inequalities are active, as shown earlier (Crippen, 1991), particularly those inequalities arising from the more challenging compact alternatives. Therefore, we selected the first $\mathbf{4 9}$ alternatives for each reference that obeyed the compactness criteria of eqn (5), using eqn (3) for the minimal radius of gyration and eqn (4) for the maximal number of contacts. In the optimization procedure, all the starting values were set to the arbitrary value of $-0 \cdot 1$, and the $\varepsilon$ terms rapidly converged to a set of first approximation values. (2) Next, we "combed" through the full list of alternatives to each reference for any alternative that violated eqn (10). Adding these to the previous list of inequalities increased the size of the problem only slightly, and the first approximation $\varepsilon$ terms were a good starting point for calculating the second approximation. Actually, this is a very efficient way to extract all alternatives that are essential from the contact energy difference viewpoint and are missed at the first step. The clever selection of alternatives in the first 2 steps is the key to being able to treat much larger sets of inequalities than before. (3) It was found that sometimes a 3rd step of refinement of the potentials is required because some alternatives that satisfy eqn (10) before step 2 do not at the end of the step. The remedy is to return to the basic set of inequalities in the lst step, repeat the combing, and produce a 3rd set of $\varepsilon$ terms from the 2 nd approximation. A 4 th step was never required.

\section{(d) Two forms of contact function}

We used the above procedure to deduce contact potentials for a training set consisting of all 69 compact proteins, excluding all homologous structures (see Table 2). (Incidentally, note that Table 2 does not list neurotoxin $\mathrm{B}, \operatorname{lnxb}$, as homologous to erabutoxins 3ebx and 5ebx, in spite of strong sequence similarity because of its noticeable shape distortion: $e_{\mathrm{g}}=1.17$ and $e_{N}=1.54$.) However, we subsequently found that on rare occasions the resulting $E$ for some of the homologous structures was greater than that of the lowest alternative. For example, for the reference bovine pancreatic trypsin inhibitor crystal structure 4pti, there is the homologous 5pti differing in r.m.s.d. by only $0.59 \AA$, yet $E(5$ pti) is an appreciable 26.7 arbitrary units greater than $E(4$ pti) and $9 \cdot 8$ above $E$ of the lowest alternative. Since the assignment of "reference" and "homologous" structures is absolutely arbitrary, this outcome ought to be considered a violation of eqn (10). Although this happens to be the only violation of this kind, we were compelled to eliminate it.

The difficulty arises from the all-or-nothing definition of a contact, as described above. We could rewrite eqn (6) as:

$$
E=\sum_{\substack{\text { contacts } \\ i, j}} V\left(d_{i j}, U\right) \varepsilon_{i j}
$$

where $V$ is the value of a contact depending on $d_{i j}$, the relevant interatomic distance, and $U$, the cutoff value. The discrete contact function we have been using (Crippen, 1991) has:

$$
V\left(d_{i j}, U\right)= \begin{cases}1 & \text { if } d_{i j} \leq U \\ 0 & \text { otherwise }\end{cases}
$$

Even slight changes in interatomic distances between 2 homologous structures may cause significantly different lists of contacts. The solution is to use a continuous contact function where $V$ becomes a smooth sigmoidal function of $d_{i j}$, going from 1 below a lower cutoff distance $L$ to 0 above an upper cutoff $U$

$$
V\left(d_{i i}, U, L\right)= \begin{cases}\frac{\left(d_{i j}-U\right)^{2}\left(2 d_{i j}-3 L+U\right)}{(U-L)^{3}} & \text { if } L \leq d_{i j} \leq \mathrm{U} \\ 1 & \text { if } d_{i j}<L \quad(13) \\ 0 & \text { if } d_{i j}>U .\end{cases}
$$

Note that eqn (12) is a limiting case of the eqn (13) when $U=L$. For contacts involving side-chain atoms, we still include the effect of possible interfering atoms $k$ near the line segment joining the interacting atoms $i$ and $j$ by defining the modified contact strength $V_{m}$ to be:

$V_{m}\left(d_{i j}, U, L\right)=V\left(d_{i j}, U, L\right) \prod_{k}\left[1-V\left(d_{i j k}, U^{\prime}, L^{\prime}\right)\right]$,

where $d_{i j k}$ is the distance from atom $k$ to the line segment joining atoms $i$ and $j$.

In order to determine suitable cutoff values for the continuous contact definition, we chose a limited training set of reference structures, their alternatives, and their homologous structures, namely, 4pti $(12,701$ alternatives and 5pti), 3ebx (12,316 alternatives and 5ebx) and 35lc $(10,483$ alternatives and $451 \mathrm{c})$. Then the cutoffs were adjusted so that each reference and its homologous structure spanned a small range of energies, while there was a large increase in energy going from the highest homologous structure to the lowest alternative. This is the only role the homologous structures played in the fitting because, otherwise, Table 2 makes it clear that homologous structures are extremely similar to their corresponding reference structures (from 0.06 to $0.74 \AA$ r.m.s.d.), making their energies so easy to fit they were not needed in the training sets. It was found that continuity of the contact function is of critical importance only for contacts involving side-chain $\mathrm{C}^{\beta}$ atoms, while the contact function form for other types of contacts may remain discrete, as shown in Table 3. Similarly, we also used only the discrete form of the contact function term responsible for possible interfering atoms near the line segment joining the interacting pair of atoms (eqn (14)) as indicated by the last line of Table 3 , where the continuous $U=L=1.4 \AA$. In what follows, we will refer to this hybrid form of the function as the "continuous contact function" and to the old version as the "discrete" one. Note that in determining the $\varepsilon$ terms, the very approximate first step of the procedure uses the discrete 
Table 3

Boundary parameters of the discrete and continuous contact functions (see the text)

\begin{tabular}{lcccc}
\hline & & \multicolumn{3}{c}{ Cutoff distances $(\AA) \ddagger$} \\
\cline { 3 - 5 } & & & \multicolumn{2}{c}{ Continuous } \\
\cline { 3 - 5 } From atom & To atom or line & $\begin{array}{c}\text { Diserete } \\
L=U\end{array}$ & $L$ & $C^{y}$ \\
\hline $\mathrm{N}$ & $\mathrm{O}$ & $3 \cdot 20$ & $3 \cdot 20$ & $3 \cdot 20$ \\
$\mathrm{~N} \dagger$ & $\mathrm{C}^{\prime}$ & $3 \cdot 90$ & $3 \cdot 60$ & $3 \cdot 60$ \\
$\mathrm{~N}$ or 0 & $\mathrm{C}^{\beta}$ & $5 \cdot 00$ & $3 \cdot 00$ & $5 \cdot 00$ \\
$\mathrm{C}^{\beta}$ & $\mathrm{C}^{\beta}$ & $9 \cdot 00$ & $6 \cdot 00$ & $9 \cdot 00$ \\
Any atom & Line joining 2 & $1 \cdot 41$ & $1 \cdot 41$ & $1 \cdot 41$ \\
& contact atoms & & & \\
\hline
\end{tabular}

$\dagger$ Because the definition of a backbone-backbone contact requires a short $\mathrm{N}-\mathrm{O}$ distance but a long $\mathrm{N}-\mathrm{C}$ distance in order to stipulate a roughly linear hydrogen bond, the sense of these limits is reversed, eompared to eqns (12) and (13).

$\ddagger L$ and $U$ denote the lower and upper distance cutoffs of the contact function, eqns (12) to (14).

form of contact function, while the more accurate continuous form was employed in the following 2 steps.

Except for treating the homologous structures, there is not a big difference between the discrete and the continuous contact functions. For example, the relationship between the discrete number of contacts and the "effective number of contacts", defined to be the sum of all contact values (eqn (13)) for the conformer according to the continuous form of the contact function, is quite linear $\left(N_{c}\right.$ (discrete $)=0 \cdot 65 N_{c}($ continuous $\left.)+4 \cdot 56\right)$ and has a correlation coefficient of 0.997 .

\section{Results}

\section{(a) Complete training set (CTS)}

Our first question was whether we could satisfy equation (10) even by including in the training set all 69 compact structures having rcadable chain length less than 256. For each reference structure we selected the first 49 compact alternatives, which produced a set of 3381 inequalities for the whole training set. After 1521 iterations of optimization the solution for the first step was found and used as the start for the next step. On the second step, 11,336 constraints were added as described above, making altogether 14,717 inequalities. The optimization converged to a solution after $\mathbf{5 8 8 8}$ iterations. Finally, on the third step only 72 new constraints were added to the 3381 from the first step (for a total of $\mathbf{3 4 5 3}$ inequalities) and 1938 iterations completed the procedure. Checking the final potential against the whole data base showed perfect agreement with equation (10) for all 69 references and all their alternatives. Thus, the 14,789 constraints $(=3381+11,336+72)$ used in all in the CTS were sufficient to predict correctly 530,062 constraints from a total of 73 proteins (including 4 non-compact structures, 3fab.L, 2fb4.L, 3fab.H and 4rhv.3 which, of course, were not in the CTS), for an average "predictive significance" of $530062 / 14789=35 \cdot 8$. Also, all the 95 homologous structures in Table 2 had contact energies less than the lowest alternative of the corresponding reference structure.

\section{(b) Reduced training set (RTS)}

Having seen that it is possible to fit all the proteins, we next tried to reduce the training set, seeking to determine the minimum number of proteins necessary to deduce a potential that could make a prediction of the same quality. Going on the theory that small and medium-sized proteins provide the most effective constraints, we first tried all reference structures having 150 residues or less. This failed in that one of the compact proteins, 2pka.B, had a number of alternatives' energies violating equation (10) and one of them was below the reference structure energy by $18 \cdot 3$ units.

On the other hand, when we excluded from the training set the 32 structures (Table 4) having reference energies in the CTS potential more than 100 units below the lowest alternative, we were successful. The amount of information about interresidue interactions contained in the remaining 37 structures (whose alternatives correspond to a total of 10,088 constrain(s) was sufficient to make correct. predictions for exactly the same proteins as before with the complete training set. Note that the average "predictive significance" of a constraint in this calculation is $\mathbf{5 0} \%$ better than with the CTS: $530062 / 10088=52 \cdot 54$.

The values of the resulting RTS parameters seem to have clear physical meaning (Table 5). For example, for sequence separations of eight residues and more (4th separation range) the largest positive (i.e. unfavorable) values are observed for interactions between pairs of positively charged sidechains of Lys and/or Arg residues (group 5 and group $5 \quad \varepsilon=9 \cdot 21$ ) or between pairs of negatively charged/polar Asp, Asn, Glu and Gin residues (group 7 and group $7 \varepsilon=4.33$ ), in agreement with the obvious electrostatic repulsion between sidechains having like charges. On the other hand, the largest negative interaction parameters are for pairs of the hydrophobic residues Leu, Ile, Cys, Met and Phe (group 3 and group $3 \varepsilon=-8.46$ ) or for these hydrophobic residues and non polar side chains of Ala and Val (group 2 and group $3 \varepsilon=-6.59$ ), thus. reflecting the tendency of these residues to form favorable hydrophobic interactions with each other.

In general, there is an apparent correlation in contact energies of native structures and their chain lengths (Fig. 3) that fits:

$$
E(\text { native })=47 \cdot 17-4 \cdot 37 N_{\text {res }}
$$

with a correlation coefficient of -0.932 . This relation may be helpful in predicting the conformation of a novel protein sequence. If the lowest proposed conformation of a protein still gives an energy well above the value expected for such a chain length, then the correct native conformation probably has not yet been suggested.

Note that all the smallest structures in the list 
Table 4

Contact energy and contact energy difference for the 86 reference proteins and their 95 homologues calculated with the final (RTS) potential of Table 5

\begin{tabular}{|c|c|c|c|c|c|c|c|c|c|}
\hline \multirow{3}{*}{$\begin{array}{l}\mathbf{P D B} \\
\text { code }\end{array}$} & \multirow[b]{3}{*}{ No. res } & \multirow[b]{3}{*}{ No. alts } & \multicolumn{7}{|c|}{ Contact energy (arbitrary units) } \\
\hline & & & \multirow[b]{2}{*}{ Ref. } & \multirow[b]{2}{*}{ Alts } & \multirow[b]{2}{*}{ Diff $\dagger$} & \multicolumn{4}{|c|}{ Homologous } \\
\hline & & & & & & No. & Min. & Max. & Diff. $\neq$ \\
\hline *3ins.A & 21 & 16521 & $-\mathbf{5 9} \cdot 0$ & $-91 \cdot 8$ & $-32 \cdot 8$ & & & & \\
\hline *2mlt.A & 26 & 15980 & $-37 \cdot 6$ & $-92 \cdot 2$ & $-54 \cdot 6$ & & & & \\
\hline$* \operatorname{lgen}$ & 29 & 15658 & $-11 \cdot 3$ & $-91 \cdot 8$ & $-80 \cdot 5$ & & & & \\
\hline *3ins. B & 30 & 15551 & $-51 \cdot 3$ & $-119 \cdot 3$ & $-67 \cdot 9$ & & & & \\
\hline *lppt & 36 & 14920 & $-35 \cdot 4$ & $-86 \cdot 1$ & $-50 \cdot 7$ & & & & \\
\hline *7api. B & 36 & 14919 & $-85 \cdot 2$ & $-122 \cdot 9$ & $-37 \cdot 7$ & & & & \\
\hline$* 4$ rhv 4 & 40 & 14506 & $7 \cdot 8$ & $-122 \cdot 5$ & $-130 \cdot 3$ & & & & \\
\hline lbds & 43 & 14199 & $-137 \cdot 7$ & $-121 \cdot 7$ & 15.9 & & & & \\
\hline lern & 46 & 13895 & $-184 \cdot 2$ & $-166 \cdot 7$ & $17 \cdot 5$ & & & & \\
\hline lfdx & 54 & 13094 & $-233 \cdot 8$ & $-211 \cdot 2$ & $22 \cdot 6$ & & & & \\
\hline $5 \mathrm{rxn}$ & 54 & 13093 & $-173 \cdot 1$ & $-136 \cdot 7$ & 36.5 & & & & \\
\hline 2ovo & 56 & 12896 & $-192 \cdot 5$ & $-175 \cdot 1$ & $17 \cdot 4$ & & & & \\
\hline 4pti & 58 & 12701 & $-213 \cdot 3$ & $-192 \cdot 8$ & 20.5 & 1 & $-202 \cdot 8$ & $-202 \cdot 8$ & $10 \cdot 0$ \\
\hline $3 \mathbf{e b x}$ & 62 & 12316 & $-197 \cdot 7$ & $-179 \cdot 8$ & $17 \cdot 9$ & 1 & $-196 \cdot 8$ & -196.8 & $17 \cdot 0$ \\
\hline lese.I & 63 & 12220 & $-150 \cdot 4$ & $-133 \cdot 3$ & $17 \cdot 1$ & & & & \\
\hline $\operatorname{lsn} 3$ & 65 & 12031 & $-204 \cdot 6$ & $-178 \cdot 0$ & $26 \cdot 6$ & & & & \\
\hline -letf & 68 & 11751 & $-302 \cdot 9$ & $-221 \cdot 8$ & $81 \cdot 1$ & & & & \\
\hline Ihoe & 74 & 11198 & $-219 \cdot 9$ & -196.5 & $23 \cdot 4$ & & & & \\
\hline *2abx.A & 74 & 11197 & $-206 \cdot 0$ & -229.7 & $-23 \cdot 7$ & & & & \\
\hline$-3 \mathrm{icb}$ & 75 & 11106 & $-358 \cdot 6$ & $-241 \cdot 0$ & $117 \cdot 6$ & & & & \\
\hline *2pka,A & 80 & 10660 & $-182 \cdot 3$ & $-254 \cdot 7$ & -72.5 & & & & \\
\hline $351 \mathrm{c}$ & 82 & 10483 & $-283 \cdot 4$ & $-274 \cdot 3$ & $36 \cdot 1$ & 1 & $-302 \cdot 1$ & $-302 \cdot 1$ & $54 \cdot 8$ \\
\hline $1 c c 5$ & 83 & 10395 & -276.5 & $-255 \cdot 2$ & $21 \cdot 3$ & & & & \\
\hline Ihip & 85 & 10222 & -278.9 & $-255 \cdot 5$ & $23 \cdot 4$ & & & & \\
\hline $2 \mathrm{~b} 5 \mathrm{c}$ & 85 & 10221 & $-303 \cdot 6$ & -249.9 & $53 \cdot 7$ & & & & \\
\hline *2gn5 & 87 & 10052 & -205.5 & $-276 \cdot 9$ & -71.4 & & & & \\
\hline$-3 f x c$ & 98 & 9138 & $-448 \cdot 1$ & $-316 \cdot 2$ & $131 \cdot 9$ & & & & \\
\hline lhvp.A & 99 & 9055 & -373.9 & $-346 \cdot 8$ & $27 \cdot 1$ & & & & \\
\hline-1 pey & 99 & 9054 & $-495 \cdot 5$ & $-324 \cdot 1$ & $171 \cdot 3$ & 5 & $-498 \cdot 6$ & $-480 \cdot 5$ & $156 \cdot 4$ \\
\hline *lwrp.R & 102 & 8813 & $-349 \cdot 7$ & $-354 \cdot 1$ & $-4 \cdot 4$ & & & & \\
\hline 5cyt.R & 103 & 8733 & $-373 \cdot 1$ & $-356 \cdot 0$ & $17 \cdot 1$ & & & & \\
\hline$-4 f d l$ & 106 & 8498 & $-500 \cdot 1$ & -357.9 & $142 \cdot 1$ & 2 & $-512 \cdot 5$ & $-492 \cdot 2$ & $134 \cdot 3$ \\
\hline lrei.A & 107 & 8420 & $-332 \cdot 9$ & $-315 \cdot 0$ & $17 \cdot 9$ & & & & \\
\hline $2 \mathrm{cdv}$ & 107 & 8419 & $-317 \cdot 2$ & $-293 \cdot 2$ & $24 \cdot 1$ & & & & \\
\hline $2 \mathrm{ssi}$ & 107 & 8418 & $-373 \cdot 4$ & $-343 \cdot 4$ & $29 \cdot 9$ & & & & \\
\hline lacx & 108 & 8343 & $-335 \cdot 8$ & $-290 \cdot 2$ & 45.5 & & & & \\
\hline$-\tilde{\mathbf{x}} \mathrm{cpv}$ & 108 & 8342 & $-600 \cdot 4$ & $-449 \cdot 2$ & $151 \cdot 2$ & 2 & $-620 \cdot 3$ & $-602 \cdot 0$ & $152 \cdot 8$ \\
\hline$-1 \mathrm{cer}$ & 111 & 8125 & $-376 \cdot 2$ & $-278 \cdot 3$ & $97 \cdot 9$ & & & & \\
\hline $2 e 2 \mathrm{c}$ & 112 & 8053 & $-370 \cdot 4$ & $-345 \cdot 9$ & $24 \cdot 6$ & 1 & $-385 \cdot 0$ & $-385 \cdot 0$ & $39 \cdot 1$ \\
\hline Ihmq.A & 113 & 7982 & -375.4 & $-353 \cdot 6$ & $21 \cdot 8$ & & & & \\
\hline 2pab.A & 114 & 7912 & $-426 \cdot 2$ & $-378 \cdot 5$ & $47 \cdot 7$ & & & & \\
\hline 2rhe & 114 & 7911 & $-373 \cdot 3$ & -369.9 & 3.4 & & & & \\
\hline *1cy3 & 118 & 7642 & $-219 \cdot 3$ & $-374 \cdot 1$ & $-154 \cdot 8$ & & & & \\
\hline-1 paz & 120 & 7509 & $-568 \cdot 4$ & $-394 \cdot 0$ & $174 \cdot 4$ & & & & \\
\hline $155 \mathrm{c}$ & 121 & 7443 & $-358 \cdot 9$ & $-323 \cdot 2$ & $35 \cdot 8$ & & & & \\
\hline lpp2.R & 122 & 7378 & $-422 \cdot 7$ & $-385 \cdot 1$ & 37.5 & & & & \\
\hline$-1 b p^{2}$ & 123 & 7314 & $-493 \cdot 4$ & $-389 \cdot 6$ & $103 \cdot 8$ & & & & \\
\hline $\operatorname{lrn} 3$ & 124 & 7251 & $-399 \cdot 7$ & $-328 \cdot 6$ & $71 \cdot 1$ & 3 & $-443 \cdot 1$ & $-401 \cdot 8$ & $73 \cdot 2$ \\
\hline$-2 \mathrm{ecy} \cdot \mathrm{A}$ & 127 & 7067 & $-552 \cdot 1$ & $-438 \cdot 6$ & 113.5 & & & & \\
\hline$-11 y z$ & 129 & 6946 & $-673 \cdot 1$ & $-578 \cdot 0$ & $95 \cdot 1$ & 14 & $-723 \cdot 2$ & $-633 \cdot 3$ & $55 \cdot 3$ \\
\hline 2aza.A & 129 & 6945 & $-488 \cdot 1$ & $-423 \cdot 5$ & $64 \cdot 6$ & & & & \\
\hline$-11 \not 21$ & 130 & 6886 & $-743 \cdot 2$ & $-378 \cdot 4$ & $364 \cdot 8$ & & & & \\
\hline lecd & 136 & 6543 & $-532 \cdot 3$ & $-505 \cdot 9$ & 26.5 & 3 & $-572 \cdot 3$ & -5554 & $49 \cdot 5$ \\
\hline$-3 f x n$ & 138 & 6430 & $-807 \cdot 5$ & $-499 \cdot 7$ & $307 \cdot 8$ & 1 & $-849 \cdot 7$ & $-849 \cdot 7$ & $350 \cdot 0$ \\
\hline 2hhb.A & 141 & 6264 & $-528 \cdot 3$ & $-501 \cdot 8$ & 26.5 & & & & \\
\hline 2sns & 141 & 6263 & $-418 \cdot 0$ & $-375 \cdot 9$ & $42 \cdot 1$ & & & & \\
\hline$-1 m b a$ & 146 & 5997 & $-668 \cdot 2$ & $-550 \cdot 0$ & $118 \cdot 1$ & 3 & $-740 \cdot 4$ & $-696 \cdot 2$ & $146 \cdot 2$ \\
\hline 2hhb.B & 146 & 5996 & $-548 \cdot 6$ & $-493 \cdot 0$ & $55 \cdot 6$ & & & & \\
\hline$-\mathbf{l f} \mathbf{x I}$ & 147 & 5944 & $-715 \cdot 3$ & $-451 \cdot 3$ & $264 \cdot 0$ & & & & \\
\hline$-2 l h \mathbf{b}$ & 149 & 5843 & $-800 \cdot 1$ & $-521 \cdot 7$ & $278 \cdot 5$ & & & & \\
\hline$-2 \operatorname{sod} .0$ & 151 & 5744 & $-600 \cdot 4$ & $-382 \cdot 4$ & 217.9 & & & & \\
\hline 2pka.B & 152 & 5695 & $-462 \cdot 5$ & $-424 \cdot 8$ & $37 \cdot 7$ & & & & \\
\hline llh4 & 153 & 5647 & $-587 \cdot 8$ & $-558 \cdot 6$ & $29 \cdot 3$ & 13 & $-647 \cdot 2$ & $-581 \cdot 8$ & $23 \cdot 2$ \\
\hline-1 mbd & 153 & 5646 & $-733 \cdot 8$ & $-582 \cdot 9$ & $150 \cdot 8$ & $\theta$ & $-809 \cdot 5$ & $-754 \cdot 2$ & $171 \cdot 3$ \\
\hline$-4 \mathrm{dfr} . \mathrm{A}$ & 159 & 5375 & $-658 \cdot 6$ & $-467 \cdot 3$ & $191 \cdot 3$ & 1 & $-584 \cdot 1$ & $-584 \cdot 1$ & 116.8 \\
\hline$-2 \mathrm{lzm}$ & 164 & 5154 & $-821 \cdot 0$ & $-549 \cdot 6$ & $271 \cdot 4$ & 34 & $-867 \cdot 1$ & -795.5 & $245 \cdot 9$ \\
\hline
\end{tabular}


Table 4 (continued)

\begin{tabular}{|c|c|c|c|c|c|c|c|c|c|}
\hline \multirow{3}{*}{$\begin{array}{l}\text { PDB } \\
\text { code }\end{array}$} & \multirow[b]{3}{*}{ No. res } & \multirow[b]{3}{*}{ No. alts } & \multicolumn{7}{|c|}{ Contact energy (arbitrary units) } \\
\hline & & & \multirow[b]{2}{*}{ Ref. } & \multirow[b]{2}{*}{ Alts } & \multirow[b]{2}{*}{ Diff. $†$} & \multicolumn{4}{|c|}{ Homologous } \\
\hline & & & & & & No. & Min. & Max. & Diff. \\
\hline 9wga.A & 170 & 4895 & $-511 \cdot 9$ & $-472 \cdot 3$ & $39 \cdot 6$ & 3 & $-529 \cdot 1$ & $-499 \cdot 3$ & $27 \cdot 0$ \\
\hline$-1 \mathrm{gcr}$ & 174 & 4726 & $-816 \cdot 0$ & -457.8 & $358 \cdot 3$ & & & & \\
\hline *1 hmg. B & 175 & 4684 & $-363 \cdot 3$ & $-560 \cdot 5$ & $-197 \cdot 2$ & & & & \\
\hline$-2 \mathrm{sga}$ & 181 & 4443 & $-725 \cdot 7$ & $-535 \cdot 6$ & $190 \cdot 1$ & & & & \\
\hline $2 \mathrm{stv}$ & 184 & 4325 & $-740 \cdot 1$ & -653.5 & $86 \cdot 6$ & & & & \\
\hline $3 a d k$ & 194 & 3944 & $-666 \cdot 1$ & $-598 \cdot 7$ & $67 \cdot 4$ & & & & \\
\hline$-2 a l p$ & 198 & 3795 & $-847 \cdot 4$ & $-634 \cdot 8$ & $212 \cdot 6$ & & & & \\
\hline-4 sbv.A & 199 & 3758 & $-769 \cdot 4$ & -618.0 & $151 \cdot 4$ & & & & \\
\hline *3fab.L & 207 & 3477 & $-637 \cdot 1$ & -535.8 & $101 \cdot 2$ & & & & \\
\hline -3gap.A & 208 & 3442 & $-839 \cdot 0$ & -723.5 & 115.5 & & & & \\
\hline-9 pap & 212 & 3309 & $-834 \cdot 1$ & $-513 \cdot 1$ & $321 \cdot 0$ & 1 & $-875 \cdot 1$ & $-875 \cdot 1$ & $362 \cdot 0$ \\
\hline$*_{2} \mathrm{fb4} . \mathrm{L}$ & 216 & 3180 & $-634 \cdot 0$ & $-454 \cdot 6$ & $179 \cdot 4$ & & & & \\
\hline -2act & 218 & 3117 & $-855 \cdot 0$ & -557.4 & $297 \cdot 6$ & & & & \\
\hline *3fab.H & 219 & 3086 & $-653 \cdot 2$ & $-543 \cdot 3$ & $109 \cdot 9$ & & & & \\
\hline$-3 \mathbf{r p 2 . A}$ & 224 & 2940 & $-1005 \cdot 9$ & $-818 \cdot 8$ & $187 \cdot 0$ & & & & \\
\hline *4rhv.3 & 236 & 2603 & $-884 \cdot 9$ & $-758 \cdot 1$ & $126 \cdot 8$ & & & & \\
\hline$-2 \mathrm{cna}$ & 237 & 2575 & $-1033 \cdot 6$ & $-643 \cdot 2$ & $390 \cdot 3$ & 1 & $-1035 \cdot 8$ & $-1035 \cdot 8$ & $392 \cdot 6$ \\
\hline -lest & 240 & 2496 & $-963 \cdot 4$ & $-687 \cdot 2$ & $276 \cdot 1$ & & & & \\
\hline-1 tim.A & 247 & 2320 & $-1088 \cdot 1$ & $-798 \cdot 5$ & $289 \cdot 6$ & & & & \\
\hline$-4 \mathrm{rhv} .2$ & 255 & 2127 & $-993 \cdot 7$ & $-738 \cdot 2$ & 255.5 & & & & \\
\hline
\end{tabular}

The 17 non-compact structures are marked by an asterisk. A - marks the 32 proteins that had large contact energy differences with all the preliminary and intermediate potentials and were therefore removed from complete training set to form the reduced one.

† Ref. is the energy of the reference structure; Alts refers to the lowest contact energy over all the alternatives and Diff. is the difference between the contact energy of the reference structure and the lowest energy over all of the alternatives.

$\ddagger$ Min. and Max. are the minimal and maximal contact energies over the list of homologues corresponding to a given reference structure (see Table 2). Diff. is the difference between the contact energy of the highest homologous structure and the lowest alternative.

(the first 7 in Table 4 and Fig. 3) are non-compact and violate the fitting condition, equation (10). However, only six of the remaining ten noncompact structures of larger size have violations. The energy margin between reference and lowest alternative is generally substantial (Table 4) except for the reference Bence-Jones protein 2rhe, which has energy only 3.4 units below an alternative derived from the related FAB-protein $2 \mathrm{fb} 4 . \mathrm{L}$

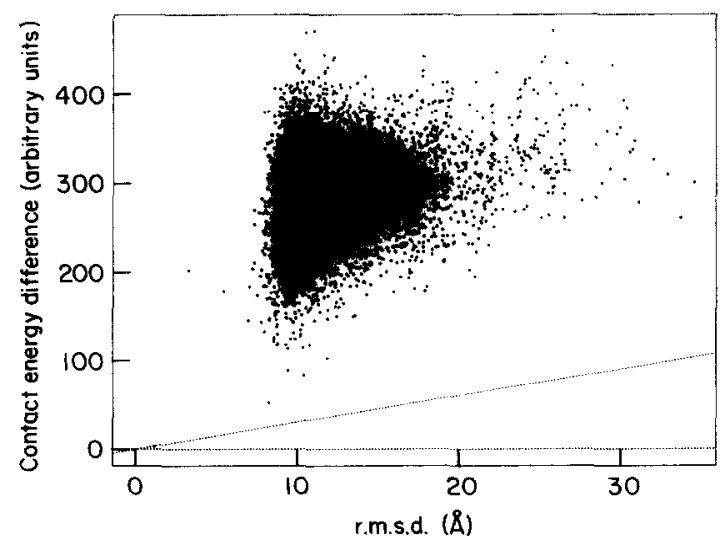

Figure 2. Contact energy difference calculated with RTS potentials versus r.m.s.d. plot for the 2rhe reference structure (114 residues), showing all 7911 alternatives. Zero contact energy difference and the threshold margin of $3 \times$ r.m.s.d. (eqns (8) and (10)) are shown by dotted lines. The alternative elosest to the reference structure (r.m.s.d. = $1 \cdot 17 \AA$ ) was generated from the crystal structure of FAB-protein $2 \mathrm{fb} 4 . \mathrm{L}$. (r.m.s.d. $=1 \cdot 17 \hat{\mathrm{A}}$ ). This is an unusual situation where $2 \mathrm{fb} 4 . \mathrm{L}$ is a close homologue of $2 \mathrm{rhe}$. The next closest alternative has r.m.s.d. $=8 \cdot 1 \AA$ and energy $52 \cdot 1$ above the reference (Fig. 2). Otherwise, Figure

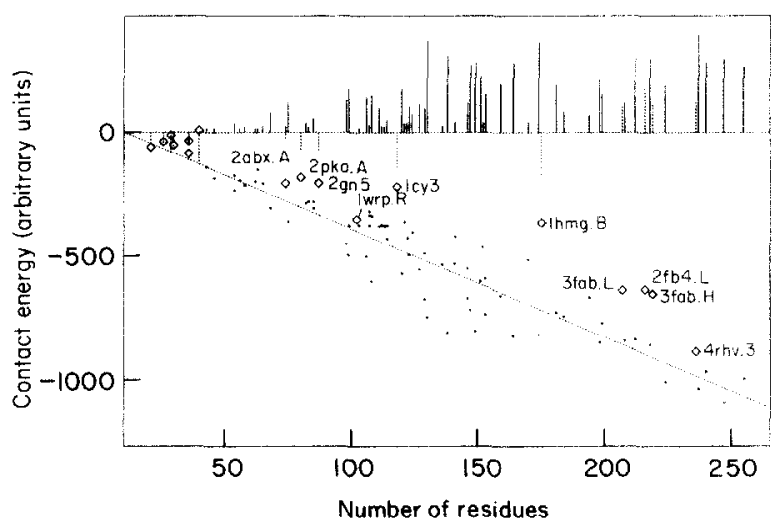

Figure 3. Contact energy of 86 reference structures versus number of residues. The 69 compact and 17 noncompact structures are shown by points and diamonds. respectively, the latter being marked by their PDB code. The PDB markers for the 7 smallest structures, 3ins.A. 2mlt.A, lgen, 3ins.B, 1ppt, 7api.B and 4rhv.4, are omitted for clarity. The upper part of the plot shows contact energy differences between the lowest energy alternative and the reference structure for each protein as lines from the zero energy level toward the respective value for the 69 compact (continuous lines) and the 17 non-compact (dotted lines) proteins. The straight line through the referenee structures was determined by linear regression to have slope $-4 \cdot 37$, intercept $47 \cdot 17$ and correlation coefficient $-0-932$. 
Table 5

Contact potentials that satisfy the 73 proteins and corresponding 95 homologous structures

\begin{tabular}{|c|c|c|c|c|c|c|c|}
\hline & $\mathrm{G}$ & ALICMF & VHS & $P$ & $\mathrm{RDEQ}$ & TKN & $\begin{array}{c}\text { Separation } 3 \\
Y W\end{array}$ \\
\hline 1 & -0.69622 & & & & & & \\
\hline 2 & $-4 \cdot 02250$ & $4 \cdot 15407$ & & & & & \\
\hline 3 & $4 \cdot 51831$ & $-2 \cdot 15759$ & $-1 \cdot 19728$ & & & & \\
\hline 4 & $8 \cdot 32046$ & -1.52758 & $-2 \cdot 17667$ & -0.25318 & & & \\
\hline 5 & $-4 \cdot 67793$ & 0.63233 & $1 \cdot 20919$ & 0.55600 & $-3 \cdot 79903$ & & \\
\hline 6 & -0.97071 & -0.89862 & $0 \cdot 13811$ & $1 \cdot 74729$ & $-8 \cdot 34442$ & $-6 \cdot 20602$ & \\
\hline \multirow[t]{2}{*}{7} & $1 \cdot 31923$ & -0.46381 & $-0 \cdot 79571$ & $-4 \cdot 71292$ & -6.05593 & -3.61441 & $-1 \cdot 34488$ \\
\hline & G & ALICMF & VHS & $\mathbf{P}$ & RDEQ & TKN & $\begin{array}{c}\text { Separation } 4 \\
\text { YW }\end{array}$ \\
\hline 1 & 0.95207 & & & & & & \\
\hline 2 & -2.97196 & $-2 \cdot 18647$ & & & & & \\
\hline 3 & 0.51624 & -5.46954 & $0-59592$ & & & & \\
\hline 4 & $9 \cdot 43824$ & 0.95249 & $1 \cdot 17324$ & $0 \cdot 81616$ & & & \\
\hline 5 & $1 \cdot 42327$ & 0.88925 & $3-15180$ & $-2 \cdot 08650$ & 0.22717 & & \\
\hline 6 & $-3 \cdot 03373$ & -1.37106 & $1 \cdot 46070$ & 1.01162 & $2 \cdot 42066$ & $0 \cdot 41988$ & \\
\hline \multirow[t]{3}{*}{7} & $3 \cdot 32498$ & 0.98535 & $0 \cdot 55464$ & $0 \cdot 03249$ & $0 \cdot 27325$ & $1 \cdot 76394$ & $-0 \cdot 32876$ \\
\hline & & & & & & \multicolumn{2}{|c|}{ Separations 5 to 7} \\
\hline & G & AV & LICMF & YHWST & $\mathbf{K R}$ & $\mathrm{P}$ & DNEQ \\
\hline 1 & $-I \cdot 66730$ & & & & & & \\
\hline 2 & 0.83544 & $2 \cdot 19482$ & & & & & \\
\hline 3 & $-0 \cdot 80084$ & $-1 \cdot 03313$ & -6.92885 & & & & \\
\hline 4 & $-5 \cdot 63378$ & $-1 \cdot 59914$ & $-1 \cdot 05550$ & -0.40860 & & & \\
\hline 5 & $1 \cdot 32582$ & $2 \cdot 20828$ & $-2 \cdot 96523$ & $5 \cdot 61379$ & $1 \cdot 27991$ & & \\
\hline 6 & $1 \cdot 94306$ & -0.51869 & $3 \cdot 80413$ & $4 \cdot 24939$ & $0 \cdot 43871$ & $-0 \cdot 10825$ & \\
\hline \multirow[t]{2}{*}{7} & $-6 \cdot 21464$ & $2 \cdot 75095$ & $-2 \cdot 41791$ & -0.24586 & 372012 & 1.57452 & 1.98596 \\
\hline & $\mathrm{G}$ & AV & LICMF & YHWST & $\mathrm{KR}$ & $\mathrm{P}$ & $\begin{array}{c}\text { Separation } \geq 8 \\
\text { DNEQ }\end{array}$ \\
\hline 1 & $-0 \cdot 40067$ & & & & & & \\
\hline 2 & -0.56931 & $-2 \cdot 62597$ & & & & & \\
\hline 3 & 0.92706 & -6.58525 & $-8 \cdot 46742$ & & & & \\
\hline 4 & $-2 \cdot 44415$ & $-0 \cdot 87669$ & $-3 \cdot 19972$ & $2 \cdot 42480$ & & & \\
\hline 5 & -0.81858 & $-1 \cdot 25143$ & -0.08153 & $-1 \cdot 73287$ & $9 \cdot 21333$ & & \\
\hline 6 & $1 \cdot 00735$ & $-1 \cdot 33631$ & 0.04413 & 0.02409 & -0.69110 & $4 \cdot 31013$ & \\
\hline 7 & $-3 \cdot 36539$ & $2 \cdot 14130$ & 1.90592 & 0.51326 & $-3 \cdot 14586$ & $3 \cdot 39357$ & $4 \cdot 33339$ \\
\hline
\end{tabular}

Potentials are deduced with only 37 proteins, the reduced training set (RTS). Classification of amino acid residue contacts is assigned by sequence separation range and by subsets of types of residues indicated by the single-letter residue code. For each of the 4 sequence separation ranges we show the symmetrie matrix of interaction parameters $\varepsilon$ for contacts between residues of the various classes.

2 is typical of the energy distribution for all the compact proteins.

\section{(c) Tests of significance of a classification}

To test the significance of the classification scheme used throughout this work (Table 5) we attempted to deduce three additional potentials from the same 37 proteins of the RTS. We used the same computational protocol as described above, only with three different classification schemes.

The first test used the best (i.e. fewest adjustable $\varepsilon$ terms) contact classification found in our earlier work (see Table 3 in Crippen, 1991). We were unable to locate a reasonable solution even after 16,000 iterations of optimization in each of the three steps. Perhaps a solution of the quality of our CTS and
RTS potentials could be found after much more computing effort, but it seems unlikely.

In the second test we used the same sequence separation classifications and the same number of residue classes in each as before in the C'TS and RTS polenlials (Table 5), but with random assignment of residue types to classes. The first step succeeded, but the second step failed by exceeding our program's limit of 15,000 on the number of constraints while "combing" the 17 th protein of the 37 in the training set. Presumably, even with a much greater limit on constraints, the calculation would fail to find a solution at great computational expense. Apparently, the classification scheme of Table 5 is not only in general agreement with conventional wisdom about residue type similarities, but the particular classification is more 
important than merely the number of adjustable $\varepsilon$ terms.

The third test was simply to interchange the residue classifications for the first and fourth separation ranges in Table 5, and then attempt to satisfy all the inequalities. Curiously enough, this succeeded, resulting in what we will refer to as the T3 parameters. With these we are able to correctly predict the same proteins as with the RTS parameters. The distribution of the contact energies of reference structures versus the number of residues with the T3 potential is approximately the same, with slightly different linear regression coefficients: the intercept is $\mathbf{2 5 \cdot 2 9}$, the slope is $-4 \cdot 49$, and the correlation coefficient is -0.918 , compared to $47 \cdot 17$, -4.37 and -0.932 , respectively, in equation (15). The root-mean-square difference between contact energies of compact reference structures calculated with RTS and T3 is only 67.4 arbitrary units, compared with the 1100 units for the total range of reference energies.

We were unable to repeat the systematic search for simpler classification schemes carried out in our earlier work because now we treat many more proteins, vastly more alternative conformations, and we demand in equation (10) not merely that the reference have energy less than or equal to each alternative, but that there be a substantial margin. Solving inhomogeneous inequalities is qualitatively different from, and more time-consuming than, solving homogeneous ones.

The RTS potentials were also checked against a representative sampling of erystal structures with fewer than 256 residues that had been added to the Protein Data Bank since 15 October 1990: 2eti (trypsin inhibitor II, 28 residues), 4tgf (human growth factor, 50 residues), lfkf (FK506 binding protein, 107 residues) and 1 cd4 (T-cell surface glycoprotein, 173 residues). These had never been seen in our laboratory until after the RTS potential had been determined. Using the same list of protein structures as before, the alternatives for each of these structures were generated. Only the structure of 4 tgf growth factor (13,495 alternatives) with apparent disturbance of compactness (parameters $e_{\mathrm{g}}=1.38$ and $e_{N}=1.51$ exceed the corresponding threshold values of 1.30 and 1.50 ) has a number of alternatives with contact energy less than the reference structure. The three others, 2eti (15,766 alternatives), lfkf (8421 alternatives) and 1 cd4 (4769 alternatives), demonstrate obvious satisfaction of equation (10) for all alternatives generated. While large proteins are relatively easy to fit, the trypsin inhibitor 2eti is a remarkably small structure that we can nonetheless successfully predict because it obeys our requirements for compactness and many internal contacts.

\section{Discussion}

It is interesting to compare our results with that of Hendlich et al. (1990), the most similar work outside our group that we are aware of. They derived many different potentials of mean force for
$\mathrm{C}^{\beta}-\mathrm{C}^{\beta}$ interactions only by surveying a database of 101 separate chains in protein $X$-ray crystal structures, listed in their Table 3. To make predictions of the folding for one protein, they would remove it from the database and use the remaining 100 to derive the effective energy of interaction as a function of distance between side-chains, broken down into 15 sequence separation classes and for each of these, all 210 residue pair type classes. Then they generated a set of alternative conformations in the same way we do, and compared their calculated energies of the native versus all its alternatives. One view of their potentials is that they consist of $210 \times 15=3150$ different histograms as a function of $C^{\beta}-C^{\beta}$ distance, while we have only $84 \varepsilon$ terms in our Table 5. However, we adjusted our $\varepsilon$ terms empirically to satisty a large number of inequalities, but their histograms are not adjustable parameters. In return, we get much greater prodictive power: a training set of 37 compact proteins invariably favors the native structure of 73 proteins over all alternative conformations. By way of comparison. their Table 7 lists 53 proteins that we would consider compact, ranging between 21 and 199 residues in length. Of these, the two corresponding potentials of mean force (denoted in their work as potentials $S$ and $\mathrm{A}$ ), derived apparently from 100 crystal structures in each case, could favor the native over the alternatives in both the $\mathrm{S}$ and $\mathrm{A}$ cases only for 34 compact proteins and two non-compact proteins.

There are a number of likely reasons for our superior predictive power. First, we derive our $\varepsilon$ terms by comparing the native conformation with misfolded alternatives, rather than surveying only native conformations for a potential of mean force. In other words, the potential must be trained by showing it what is wrong as well as what is right. Secondly, we find it crucial to deal only with compact native conformations, as judged both from the radius of gyration and from the relative number of contacts. We cannot account for the crystal structure of an isolated non-compact polypeptide chain when its conformation is stabilized by intermolecular contacts in the crystal, and we suspect this has led to some of the difficulties experienced by the Sippl group, since they used both compact and non-compact native conformations. Thirdly, we find that backbone-backbone and epecially backboneside-chain interactions are important (see the $G$ columns in Table 5), whereas they considered only side-chain-side-chain interactions.

A priori, one might assume the classification scheme for residue-residue interactions is very important. The assumption is based on conventional wisdom about grouping together helixformers versus helix-breakers for short-range interactions, and grouping according to hydrophobicity for medium and long-range interactions. Indeed, this is the line of reasoning that led to the classification scheme in Table 5, as previously set forth in Crippen (1991), and subsequently used to produce the CTS and RTS potentials. However, our classification is certainly not unique, as demonstrated by 
the success of the T3 potential, where the classifications for the first and fourth separation ranges were interchanged. Although the RTS potential is very powerful in its ability to satisfy a half million inequalities, other equally good potentials could be found, possibly involving fewer parameters and possibly having even better predictive power.

In our approach, we are happy to see that some kinds of trouble simply do not arise. For example, although lhvp.A is not an experimentally determined structure, but was rather postulated by homology modeling (Weber et al., 1989), it nonetheless can be easily accounted by our contact function, whereas it could not be predicted by Hendlich $e t$ al. (1990). As another example, we utterly disregard any ligands or prosthetic groups in proteins, even large ones covalently attached to the polypeptide chain. Even so, we observe no correlation between the presence or absence of prosthetic groups and the quality of our predictions, just as long as the native is compact according to our criteria in equation (5).

It is worth noting that the range of contact energies for compact and non-compact alternatives calculated with the RTS potential are approximately the same. Both types of alternatives may be found among the very best (which are, of course, always higher than the reference structure energy) and the very worst. This means, in particular, that one must consider both types of alternatives when forming the set of inequalities, equation (10), rather than only compact ones. This finding runs against one's intuition that compact structures always have lower contact energy.

The major improvement of this work over our previous effort (Crippen, 1991) is the introduction of a substantial margin $T>0$ in equation (10) that becomes small when the r.m.s.d. becomes small, coupled with a continuous contact function that guarantees a small difference in contacts for a small r.m.s.d. For example, the reference structure 5cyt.R has an alternative derived from lcer with r.m.s.d. $=0 \cdot 47 \AA$, 2rhe has an alternative from $2 \mathrm{fb} 4 . \mathrm{L}$ with r.m.s.d. $=1 \cdot 17 \AA$, 1 lyz has an alternative from $1 \mathrm{lzl}$ with r.m.s.d. $=1.93 \AA$, and $2 \mathrm{hhb} . \mathrm{B}$ has an alternative from $1 \mathrm{mbd}$ with r.m.s.d. $=1.92 \AA$. Then, quite naturally, all these "homologous" alternatives have energies only slightly above the corresponding reference structure's, but still satisfy equation (10) by a small margin. The only exception is the $2 \mathrm{hhb} . \mathrm{A}$ reference structure for which the lowest energy alternative lies 55.6 units above the reference, yet has a large r.m.s.d. $=9.5 \AA$, compared with the second lowest alternative at $70 \cdot 7$ units above the reference, yet differing in conformation by only $1.92 \AA$. However, this result is not unexpected because a $2 \AA$ r.m.s.d. is enough to allow a considerable change in the contacts.

It is especially interesting to note that the "novel" folding pattern found in the recently determined n.m.r. and X-ray crystal structures of $1 \mathrm{fkf}$, FK506 binding protein (Michnick et al., 1991; van Duyne et al., 1991), is not new from the viewpoint of interatomic contact arrangements, given that we can correctly predict it on the basis of the reduced training set of 37 old protein structures. This finding allows one to hope that only minor readjustments of the contact potential will be required to keep a high level of predictive power as more proteins are considered.

In spite of the encouraging results we have obtained so far, there are two special cases we must treat in future versions of this potential. First, sequence homologues (see Table 2) are now correctly handled in the analysis without even being employed in the derivation of the potential, but we have not paid special attention to proteins having very similar conformation, yet low sequence identity. Instead, such pairs of proteins were used only in the general fashion to generate alternative conformations for each other. Presumably, we should demand that the two different sequences applied to essentially the same conformation should produce very similar contact energies. Work is in progress to at least see what the RTS potential says about such structural homologues.

The second case is that of non-compact native proteins, which we have so far simply excluded from the derivation of our potential as well as its testing. We find that for such a reference structure there are generally many alternatives having substantially lower contact energies. However, there are apparently very few examples of protein crystal structures where a polypeptide chain fails our compactness test without having significant interactions with neighboring chains. Work is in progress to treat such crystal structures as multimeric aggregates of polypeptide chains such that the multimer is compact.

The results presented here on the contact energy approach allow one to conclude that the problem of identifying the correct fold out of a large but discrete set of alternatives is basically solved. Given such a powerful tool for identifying the native fold, our next goal is to implement a method to suggest possible "native" folds for a given amino acid sequence when the correct answer is not known and when it is not just a segment out of an already determined crystal structure.

This work was supported by grants from the National Institutes of Health (GM37123) and the National Institute on Drug Abuse (DA06746). We are indebted to the reviewers for their helpful remarks and concerns, and to Steven Bryant for kindly providing his PKB software.

\section{References}

Abola, E. E., Bernstein, F. C., Bryant, S. H., Koetzle, T. F. \& Weng, J. (1987). Protein data bank. In Crystallographic Databases-Information Content, Software Systems, Scientific Applications (Allen, F. H., Bergerhoff, G. \& Sievers, R., eds), pp. 107-132, Data Commission of the International Union of Crystallography, Bonn/Cambridge/Chester.

Bryant, S. H. \& Amzel, L. M. (1987). Correctly folded proteins make twice as many hydrophobic contacts. Int. J. Pept. Protein Res. 29, 46-52. 
Chiche, L., Grigoret, L. M., Cohen, F. E. \& Kollman, P. A (1990). Protein model structure evaluation using the solvation free energy of folding. Proc. Nat. Acad. Sci., U.S.A. 87, 3240-3243.

Crippen, G. M. (1991). Prediction of protein folding from amino acid sequence over discrete conformation spaces. Biochemistry, 30, 4232-4237.

Damuschun, G., Müller, J. J., Pürschel, H.-V. \& Sommer, G. (1969). Berechnung der Form kolloider Teilchen aus Röntgen-Kleinwinkeldiagrammen. Monatsh. Chemie, 100, 1701-1714.

Eisenberg, D. \& McLachlan, A. D. (1986). Solvation energy in protein folding and binding. Nature (London), 319, 199-203.

Hendlich, M., Lackner, P., Weitckus, S., Floeckner, H., Froschauer, R., Gottsbacher, K., Casari, G. \& Sippl, M. J. (1990). Identification of native protein folds amongst a large number of incorrect models. $J$. Mol. Biol. 216, 167-180.

Jurs, P. C. (1986). Computer Software Applications in Chemistry, pp. 198-199, John Wiley, New York.

Lüthy, R., Bowie, J. U. \& Eisenberg, D. (1992). Assessment of protein models with three-dimensional profiles. Nature (London), 356, 83-85.

McLachlan, A. D. (1979). Gene duplications in the struc- tural evolution of chymotrypsin. J. Mol. Biol. 128 , $49-79$.

Michnick, S. W., Rosen, M. K., Wandless, 'I. J., Karplus, M. \& Schreiber, S. L. (1991). Solution structure of FKBP, a rotamase enzyme and reseptor for FK506 and rapamycin. Science, 252, 836-839.

Novotny, J., Bruccoleri, R. \& Karplus, M. (1984). An analysis of incorrectly folded protein models. $J . \mathrm{Mol}$. Biol. 177, 787-818.

Novotny, J., Rashin, A. A. \& Bruccoleri, R. E. (1988). Criteria that discriminate between native proteins and incorrectly folded models. Proteins: Struct. Funct. Genet, 4, 19 . 30.

Sippl, M. J. (1990). Calculation of conformational ensembles from potentials of mean force. J. Mol. Biol. 213 , 859-883.

van Duyne, G. D., Standaert, R. F., Karplus, P. A., Schreiber, S. L. \& Clardy, J. (1991). Atomic structure of FKBP-FK506, an immunophilin-immunosuppressant complex. Science, 252, 839-842.

Weber, I. T., Miller, M., Jaskolski, M., Leis, J., Skalka, A. M. \& Wlodawer, A. (1989). Molecular modeling of the HIV-l protease and its substrate binding site Science, 243, 928-931. 